\title{
SEXUALIDADES EN FUGA: CUERPO E IDENTIDAD EN LA LITERATURA Y EL CINE DE MARTÍN REJTMAN
}

\author{
Atilio Raúl Rubino \\ Instituto de Investigaciones en Humanidades y Ciencias Sociales \\ Facultad de Humanidades y Ciencias de la Educación \\ Universidad Nacional de La Plata \\ Consejo Nacional de Investigaciones Científicas y Técnicas
}

Resumen: Este artículo busca realizar un análisis de las sexualidades en la obra literaria y cinematográfica de Martín Rejtman. En algunos textos del autor, como en el cuento "Algunas cosas importantes para mi generación" (1992) o en la película Rapado (1992), pueden verse sexualidades que se encuentran en movimiento, que parecen no obedecer al binarismo heterosexual/homosexual, sino que encuentran un punto de fuga a la racionalidad sexual. Por otro lado, los cuerpos en varios de los films y relatos de Rejtman adquieren una enorme importancia, ya que se entraman con los desplazamientos de las identidades. Éstas se juegan en unos cuerpos tecnológicos, cuerpos protésicos, cuerpos cyborgs, que están atravesados por discursos que los dicen $y$, al hacerlo, los engendran. Las sexualidades, en este sentido, oscilan entre lo decible y lo indecible.

Palabras clave: Identidades, sexualidades, cuerpo, Martín Rejtman.

\begin{abstract}
The purpose of this article is to analyze sexualities in Martin Rejtman's literary and film work. In some texts by this author, such as the short story "Algunas cosas importantes para mi generación" ("Some Things That Are Important for My Generation", 1992) or in the film Rapado (1992), we can see sexualities that are in motion, that seem not to abide by the binary heterosexual/homosexual, but seem to find a vanishing point from sexual rationale. Bodies in several of Rejtman's films and stories, however, acquire much importance, since they are intertwined with identity displacements. These displacements take place in bodies that are technological, prosthetic, cyborgs, which are determined by the discourses that utter them and, by doing so, engender them. Sexualities, in this sense, oscillate between what can and cannot be uttered.
\end{abstract}

Keywords: Identity, Sexualities, Body, Martín Rejtman 


\section{Cuerpos cyborgs, identidades, tecnología}

Martín Rejtman es considerado uno de los precursores del Nuevo Cine Argentino. Su primer largometraje, Rapado, realizado durante 1992 y estrenado recién en 1996, marca un quiebre en la cinematografía nacional y en las formas de representación. Tanto sus películas como su obra literaria dan cuenta de una nueva época. ${ }^{1}$

El presente trabajo busca realizar un análisis de las identidades en la literatura y el cine de Martín Rejtman, con especial énfasis en la corporalidad y la sexualidad. Para esto, se toman conceptos e ideas provenientes de los estudios queer y la teoría postestructuralista, fundamentalmente en el tratamiento de las identidades y los cuerpos. En particular, se trabaja con la crítica del postestructuralismo a la idea moderna de identidad entendida como algo idéntico, fijo, sostenido en el tiempo, con unidad y coherencia y las reelaboraciones que realiza Judith Butler (1990 y 1993)², así como las conceptualizaciones de

1 Además de Rapado (1992), Silvia Prieto (1999) y Los Guantes Mágicos (2003) y la reciente Dos disparos (2014), sus cuatro largometrajes de ficción, Rejtman ha dirigido Copacabana (2006), un documental sobre el carnaval de la comunidad boliviana en Buenos Aires, Entrenamiento Elemental para Actores (2009, junto con Federico León), realizada para Canal 7, y dos cortometrajes, Doli vuelve a casa (1984-2004) y Sitting on a Suitcase (1986). Entre su obra literaria hay que mencionar los libros de cuentos Rapado (Planeta, 1992), Velcro y Yo (Planeta, 1996), Literatura y Otros Cuentos (Interzona, 2005) y Tres Cuentos (2012), así como la publicación de los guiones de Silvia Prieto (Norma, 1999), de Entrenamiento Elemental para Actores, en colaboración con Federico León (La Bestia Equilátera, 2013) y de Rapado / Silvia Prieto /Los guantes mágicos (Beatriz Viterbo, 2014).

2 Particularmente, la consideración de la dimensión discursiva en la constitución del sexo y del género y su teoría de la performatividad, según la cual la materialidad resulta en última instancia del efecto de discursos en un marco social y cultural. 
Beatriz Preciado (2014) sobre el régimen actual de control de cuerpos y subjetividades, al que denomina farmacopornográfico. Preciado reformula la teorización sobre las "sociedades de control" que hace Deleuze en la posdata a Mil mesetas de 1990 según el cual en la actualidad la lógica del encierro y vigilancia de la fábrica, que mencionaba Foucault (1992), es reemplazada por la del control continuo que implica la competencia y el mérito de la empresa. ${ }^{3}$ Para Preciado, ya no se controlan a los sujetos mediante la disciplina externa, sino que las tecnologías de subjetivación actúan desde adentro, se convierten en cuerpo (Preciado, 2014, p. 72). Denomina farmacopornográfico al actual régimen de control y disciplinamiento porque se trata de "nuevas tecnologías del cuerpo (biotecnologías, cirugía, endocrinología, etc.) y de la representación (fotografía, cine, televisión, cibernética, etc.) que infiltran y penetran la vida cotidiana como nunca lo habían hecho" (Preciado, 2014, pp. 70-72). ${ }^{4}$

3 Según, Deleuze, en las sociedades de control ya no se tiene a los individuos encerrados, vigilados, sino que lo que se obstaculiza es la entrada, el acceso: para poder pertenecer hay una serie de barreras, sobre todo económicas, que deben ser flanqueadas con la lógica de la empresa. A su vez, ya no se producen bienes sino que se venden servicios y el aprovechamiento del tiempo propio de la producción es reemplazado por la venta y el marketing. El individuo tiene que cumplir metas, autosuperarse, crecer, ascender, aumentar sus ganancias. La empresa impone "una modulación de cada salario, en estados de perpetua metastabilidad que pasan por desafíos, concursos y coloquios extremadamente cómicos" (Deleuze, 1991).

4 Preciado ve al porno y la industria farmacológica como modelos utópicos de toda empresa: la lógica excitación/frustración del porno y la lógica de la medicina ya no para curar enfermedades sino para concebirlas, crearlas o, en realidad, construir lo humano, delimitar lo normal.

№3. Primer Semestre de 2015 
Así, en muchos de los textos de Martín Rejtman encontramos cuerpos atravesados por las tecnologías, tanto de la representación (cine, pornografía, literatura, etc.) como de la materialidad del cuerpo (medicamentos, alcohol, alimentación, ejercitación, etc). Un caso paradigmático es el de Los guantes mágicos, ya que allí los cuerpos se dicen, se mencionan, son definidos y constituidos por los discursos médicos y farmacológicos, así como por la pornografía como materia también discursiva. Las enfermedades, por ejemplo, primero se enuncian y luego se hacen carne. Pero no sólo se trata de la dimensión discursiva sino también material. En muchos casos, las tecnologías se vuelven prótesis, parte de una maquinaria mayor de la que también el cine y la literatura forman parte como constructores de sentido. Así, en muchos de los relatos (literarios y cinematográficos) de Martín Rejtman se puede hablar de cuerpos cyborg ${ }^{5}$, hechos de parte orgánica y parte artificial, tecnológica. ${ }^{6}$

Pero aunque los cuerpos aparezcan como el producto de dispositivos de subjetivación -entre los que se puede

5 Donna Haraway define al cyborg como "un organismo cibernético, un híbrido de máquina y organismo, una criatura de realidad social y también de ficción" (1995, p. 253) que rompe con las separaciones entre ser viviente y máquina (1995, p. 258) y entre humano y animal (1995, p. 256) y afirma: "a finales del siglo XX -nuestra era, un tiempo mítico-, todos somos quimeras, híbridos teorizados; en unas palabras, somos cyborgs" (1995, p. 254).

${ }^{6}$ Paula Sibilia hace hincapié en la imposibilidad de distinguir entre lo orgánico y lo artificial en el hombre actual, al que denomina, por eso, "hombre postorgánico", aquel en el que ya no se puede seguir insistiendo con la distinción tradicional de occidente entre "physis y techné (en términos griegos) o entre natura y ars (en términos latinos); lo natural y lo artificial." (Sibilia, 2005, p. 69). 
mencionar como uno de los principales al cine (De Lauretis, 1989)-, en muchos casos los personajes de Rejtman logran liberarse del yugo lingüístico que los constituyen y encuentran una salida a la sujeción mediante el sinsentido y los puntos de fuga. Es el caso de los cuerpos con valor de objeto de mercado que circulan en textos como Silvia Prieto, Los guantes mágicos y algunos de sus cuentos; cuerpos que, como objetos, ingresan en un intercambio simbólico-mercantil del que sólo se escapan por momentos mediante gestos micropolíticos de rebeldía ante los sentidos construidos previamente, heredados. Desde la modernidad una serie de discursos como la medicina, la psicología, el jurídico, etc. han ido definiendo los cuerpos mediante dispositivos biopolíticos que delimitan lo humano separándolo de lo anormal, lo animal, lo monstruoso y no humano (Agamben, 1998, p. 11). En este sentido, se puede entender que el cuerpo surge como consecuencia de una serie de técnicas y de discursos que lo van determinando (Sloterdijk, 2003) y que constituyen la 'verdad' sobre el cuerpo. En ese sentido, es producto de la maquinaria de las modernas biopolíticas que administran la vida, normalizan las subjetividades y docilizan el cuerpo determinando a su vez lo humano y escindiendo lo no humano.

En los textos de Rejtman que se mencionan aquí encontramos una tensión entre disciplinamiento discursivo y material de los cuerpos y el intento por desligarse del mismo. Se trata de pequeños gestos micropolíticos de resistencia que, mediante la errancia y el sinsentido, escapan por un momento a la lógica biopolítica de la subjetivación/sujeción. 


\section{Personajes errantes, inercia e identidades}

Es evidente que entre los relatos literarios y las películas de Martín Rejtman existe una fuerte unidad. Rocío Gordon (2001) denomina al estilo de Rejtman "estética de la inercia":

Sus textos y películas crean un mundo aparentemente sin motivaciones que podría estar formulando una mirada sobre la contemporaneidad. La base de esta estética radicaría en la postulación de una movilidad generada por una concatenación de eventos, pero que no tienen ni causas ni finalidades concretas. (p. 290)

Los personajes de Rejtman no persiguen una finalidad ni se mueven motivados por razonamientos o decisiones de importancia, sino que actúan de manera caprichosa, infundada. Se caracterizan por la apatía, pues pareciera que todo les da lo mismo.

En ese contexto de personajes que no tienen un fin (Bernini, 2008), las identidades aparecen fracturadas, descolocadas, descentradas. Los personajes son tratados narrativamente como objetos (muchas veces, objetos de mercado), y, en cambio, los objetos adquieren una importancia desmedida, una densidad simbólica en la que parecieran radicar las identidades. $^{7}$

7 El ejemplo más claro es el de la película Silvia Prieto (1999), cuyos personajes parecen no tener rasgos centrales o personales que los distingan y, en cambio, se caracterizan por su movilidad. Esto se puede ver en el intercambio de las parejas de la película SilviaMarcelo y Brite-Gabriel y en la tercer pareja, Garbuglia-Marta, que se conocen por un programa de televisión. Asimismo, hay una serie de objetos y elementos que pasan de mano en mano y van obteniendo una densidad mayor que los propios personajes, como 
Por su parte, Mariana Sanjurjo (2007) trabaja en profundidad el tema de la identidad en las películas de Rejtman a partir de tres ejes: los nombres, los cuerpos y los lugares. Según Sanjurjo, en las películas de Rejtman se produce una "puesta en tensión de estructuras identitarias" (p. 138) entendidas en términos modernos, es decir,

la unidad de consciencia de un sujeto que es dueño de sus propios pensamientos, acciones y cuerpo, y puede atribuirlos todos a un origen inequívoco (...). En contraposición a esta noción de identidad caracterizada por la unidad, la propiedad de sí y la transparencia (...), la noción de identidad que se despliega en los filmes de Rejtman resiste desde la tensión los intentos por reconducirla a un núcleo elucidado o elucidable de mismidad. (p. 138)

\section{Sexualidades en fuga}

La presencia de sexualidades disidentes en la obra de Rejtman es escasa. Sin embargo, pensada desde esta perspectiva se puede hablar de sexualidades en fuga, descentradas, que no son idénticas a sí mismas. En algunos textos culturales del autor, como en el cuento "Algunas cosas

el saco Armani, la lámpara de botella, el jabón Brite, la muñequita Silvia Prieto, el nombre de la protagonista, el canario, el tapado y el contestador automático, entre otros. Muchos de estos elementos, a su vez, sirven como nombres, dan nombre a los personajes y, con ello, le dan carnadura, densidad interior. Los protagonistas se definen más por estos objetos que son variables, intercambiables, que por una suerte de interioridad inmóvil o esencial, inexistente en estos personajes de Rejtman.

№3. Primer Semestre de 2015 
importantes para mi generación" (incluido en el volumen Rapado de 1992) o en la película Rapado, pueden verse sexualidades que se encuentran en movimiento, que parecen no obedecer al binarismo heterosexual/homosexual, sino que encuentran un punto de fuga a la racionalidad sexual.

En la película Rapado (1992) puede leerse un subtexto homoerótico ausente en el cuento homónimo que la precede. A Lucio (Ezequiel Cavia), su protagonista, le roban la moto al inicio de la película. Lo llamativo es que, cuando se produce el robo, Lucio estaba llevando en su moto al ladrón. Esto nos puede permitir pensar que se trata de un encuentro sexual casual. Además de la moto, le roba la billetera y las zapatillas. Cuando intenta robarle el reloj, Lucio se da cuenta de que no lo tiene y recuerda dónde lo había dejado. Estos elementos que adquieren espesor simbólico son algunos de los agregados de la versión cinematográfica que se suman al pelo y el hecho de raparse y al robo de la moto, centrales en el cuento homónimo en el que se basa (Rejtman, 2007, pp. 65-69). La ausencia del reloj dará comienzo, por un lado, a la relación con Gustavo (Gonzalo Córdoba), a quien le pregunta la hora y con quien se va a encontrar en varias oportunidades en la película, ya que se produce entre ambos una especie de flirteo que concluirá, hacia el final, con Lucio yendo a dormir a la casa de Gustavo. Sin embargo, la primera vez que se ven, Gustavo está con una chica, probablemente su novia. Por otro lado, la escena en la que recupera su reloj también está marcada como un encuentro sexual. Lucio recuerda dónde lo dejó y va a buscarlo, toca el portero eléctrico y dice "¿Ezequiel? Soy Lucio, ¿me ubicás?", lo que puede indicar que no se conocen 
demasiado o que pudo haber sido un encuentro de una única noche. El arco narrativo se cierra con Lucio en la casa de Gustavo, lo que ocurre después de su intento fallido de fuga. A su vez, Damián (Damián Dreizik) se acerca a la que era la novia de Gustavo. No sabemos qué pasa esa noche, pero cuando el hermanito entra en la habitación de Gustavo, Lucio y éste duermen en la misma cama. Cuando Lucio se va de la casa de Gustavo se da cuenta de que también se olvidó el reloj. Esta trama, si bien no constituye una clara relación homosexual, permite hacer una lectura que entienda las sexualidades de estos personajes en continuo movimiento. La errancia y la fuga típica de los personajes de Rejtman parecen también definir a la sexualidad en este film. Asimismo, el límite entre la amistad entre hombres y la relación sexual aparece también difuso, así como la separación heterosexual / homosexual.

Así como en Rapado, también en el cuento "Algunas cosas importantes para mi generación", se insinúa la homosexualidad de los personajes, pero con cierta apatía, como si diera lo mismo, o bien, una sexualidad en movimiento, no fijada ni sistematizada como un compartimento estanco. El narrador sale el sábado a la noche con su hermano Matías, Fabián, un amigo de éste, y el hermano de Fabián. Van a un cine porno a hacer tiempo antes de llevar al hermano de Fabián al aeropuerto para viajar a Río de Janeiro. Después de un rato, se produce un incidente y Matías y Fabián van a quejarse, buscan al acomodador y, enojados, deciden irse. Recién entonces el narrador se da cuenta de que estaban mirando una película gay: "Matías y Fabián se pararon y yo aproveché para hacer lo 
mismo. Recién entonces me di cuenta de que en la película que nos había tocado había sólo hombres" (Rejtman, 2007, p. 92). La expresión "la película que nos había tocado" puede ser una forma irónica de referirse a la película elegida por Matías y Fabián, pero también puede ser una forma de negar e invisibilizar el deseo sexual homoerótico de su hermano y su amigo, o el suyo propio en vistas a una reorientación del deseo hacia la heterosexualidad elucidable e inteligible.

\section{Cuerpos protésicos}

Por otro lado, los cuerpos en varios de los films y relatos de Rejtman adquieren una enorme importancia, ya que se entraman con los desplazamientos de las identidades. Éstas se juegan en unos cuerpos tecnológicos, cuerpos protésicos, cuerpos cyborgs, que están atravesados por discursos que los dicen y, al hacerlo, los engendran. En el caso de Los Guantes Mágicos (2003) se puede hablar, en términos de Beatriz Preciado (2002), de cuerpos protésicos. Los personajes completan su entidad con objetos que los complementan y sin los cuales están incompletos: el auto para Alejandro (Gabriel Fernández Capello), las pesas y aparatos de gimnasio para Luis (Diego Olivera), su disco para Piraña (Fabián Arenillas). En los casos de Susana (Susana Pampin), Cecilia (Cecilia Biagini) y Leonardo (Leonardo Azamor), por otro lado, tenemos cuerpos-fármaco. Se relacionan entre sí a partir de la enfermedad, los síntomas y los medicamentos. Así, resultan cuerpos tecnologizados por el aparato médico y farmacológico, 
son cuerpos discursivos que se dicen, se pronuncian; según Mariana Sanjurjo (2007), "las cuestiones del cuerpo en su mayor parte se cuentan, se nombran, como para no olvidar que el cuerpo siempre está ya atravesado por el lenguaje (incluso en la acción muda), que no hay experiencia del cuerpo sin más, que el cuerpo es también interpretación" (p. 144). Las enfermedades y sus síntomas aparecen primero enunciadas y luego se hacen carne. Como actos performativos del lenguaje, las palabras se hacen cuerpo. Estos personajes son cyborgs, cuerpos tecnológicos, pero asexuados: la libido se fija en los objetos y no en cuerpos humanos. En esta película, la sexualidad es vista de manera distanciada y deconstruida. No hay ni deseo ni placer sexual. Los actos sexuales forman parte del mismo intercambio de objetos y personas, son un bien de mercado o forman parte del deambular errante de los personajes, de la maquinaria cotidiana, de la rutina que los aliena. Se constituye un cuerpo-máquina. El cuerpo de Luis, el actor porno, por ejemplo, es construido por los fierros, los aparatos de gimnasio, y su alimentación. Su cuerpo es su trabajo. Es un cuerpo pornográfico. El sonido del jadeo de la ejercitación y del acto sexual filmado para una película porno se confunden y generan como una música, una melodía, que es también el ruido monótono de una máquina, como ocurría con la caja registradora en el cuento "Barras" (Rejtman, 2011, pp. 39-71), de una fábrica posmoderna que elabora y moldea cuerpos. Además, cuando todos ven la película porno que Luis filmó en Argentina, ni siquiera su hermano puede distinguir su cuerpo deshumanizado (objeto) en la maquinaria pornosadomasoquista. Si pensamos en términos de lo que Beatriz 
Preciado (2014) llama régimen farmacopornográfico, es decir el régimen actual en el que los sujetos ya no son controlados mediante un disciplinamiento externo, como sostenía Foucault (1977), sino que las tecnologías de subjetivación actúan desde adentro, se convierten en cuerpo, entonces estos cuerpos de Los Guantes Mágicos serían una estilización cómica de los cuerpos entendidos en términos posmodernos, una dimensión que remite a, en palabras de Mariana Sanjurjo (2007), "una no claridad de las fronteras, a zonas donde lo propio es ya irremediablemente inapropiable, y a la sospecha de que incluso la materialidad del cuerpo es siempre ya máscara, de que no hay desnudez posible" (p. 145).

Algo similar puede decirse del personaje de Lucio en el cuento "Rapado". Cuando pierde su moto, objeto que lo completaba, decide raparse la cabeza. De manera simbólica, se trata de vaciar la cabeza de los significantes que son ajenos, impuestos por la generación anterior, aquella que usó el pelo largo como rebeldía frente a las normas y como símbolo de liberación del cuerpo. Al respecto, es interesante mencionar el cuento "Algunas cosas importantes para mi generación" (Rejtman, 2007, pp. 87-112). Desde su título resulta muy irónico respecto a los sentimientos generacionales. El cuento comienza así: "Hay ciertas cosas que mi novia me dice demasiado seguido. Por ejemplo, el sábado pasado no se cansó de repetirme que quería que me cortara el pelo" (p. 87). Aquí aparece como algo muy importante el pelo, como algo constitutivo de lo que esta persona es. Sin embargo, no tiene el mismo significado que tenía el pelo largo para la generación anterior. Aquí no se hace significar libertad al pelo: "Entré al 
baño, me desvestí y me metí bajo la ducha. El agua pegó contra mi cuerpo y tiré la cabeza hacia atrás: ahora que tenía el pelo completamente mojado pensé que nada en el mundo podía hacer que me lo cortara" (p. 88). ${ }^{8}$

\section{Conclusiones: el sinsentido como línea de fuga}

Según Beatriz Sarlo (2003), Rejtman da cuenta de una época de vaciamiento ideológico y político, de "un mundo sin cualidades, un mundo del postrabajo, de identidades planas, sin volúmenes" (p. 142). Sarlo afirma que estos tipos de trabajo, sólo cuantitativos "no hacen a la identidad del sujeto, no le proveen un suelo que lo constituya" (p. 134). Elsa Drucaroff (2011), en cambio, encuentra gestos de rebeldía e inconformismo en la banalidad y el capricho de sus personajes

8 Esta relación con la generación anterior también puede verse en Los Guantes Mágicos. Los personajes de esta película están cerca de los cuarenta, fueron jóvenes en los 70 . Lo que marca el puente con esa época es el recital de León Gieco que funciona como Leitmotiv en la película. Se trata de la canción "Hombres de hierro" interpretada en el Buenos Aires Rock, 1971. Cada vez que aparece la canción en la televisión, los personajes se quedan mirando paralizados. Como comenta el propio Rejtman: "Tiene que ver con el estado de un personaje de cerca de 40 años hoy, en el momento de hacer la película, y el estado de ese personaje veinte años antes. Ve ese video y podría ser una de las personas que está entre el público. Se ven planos del público. Yo me encontré un día haciendo rapping, viendo esa escena de "Rock hasta que se ponga el sol" en la televisión, y me quedé boquiabierto: ‘¿Qué es esto que estoy viendo?'. ¿Cómo pudimos haber llegado hoy a lo que llegamos? ¿Cómo puede ser que hayamos sido así, que hayamos tenido esa frescura, esa ingenuidad?" (Bernini, 2008, p. 83). Cuando los personajes se enfrentan a este video, es como si se vieran a sí mismos y no supieran qué pasó con ellos, como si no se reconocieran, porque aquello que fueron, por lo que lucharon y en lo que creyeron se dejó atrás para (sobre)vivir en un mundo gobernado por la apariencia, el mercado, un mundo sin posibilidades de trascendencia ni personal, ni mucho menos, grupal, generacional. 
(p. 125). En esa errancia que los caracteriza, en esa movilidad constante, Drucaroff ve la ruptura de los puentes intergeneracionales (p. 323), la falla en la generación anterior que no ha sabido hacerse cargo de sus fracasos y dejar lugar a los más jóvenes. Desde esta perspectiva, raparse la cabeza es oponerse a ese sistema de sentidos heredado y obstruido, pero dejarse el pelo largo también lo es, porque el cuerpo comienza a significarse a sí mismo, comienza a ser solamente cuerpo, lo que no es para nada poco.

A modo de conclusión, se puede decir que Rejtman da cuenta de nuevas realidades que no se podían contar con el sistema de representación anterior (sobre todo cinematográfico). De esta forma, los cuerpos aparecen saturados por esos discursos sociales que hegemonizaron el campo cinematográfico. La sexualidad resulta así atravesada y cargada por esos discursos. Se puede hablar de sexualidades en movimiento, en fuga, no definidas o, al menos, no desde criterios de racionalidad sexual. Por ejemplo, los personajes en muchos casos parecen no tener relaciones sexuales, sino que éstas aparecen solapadas, no marcadas, asordinadas. No intercambian fluidos corporales sino objetos, enfermedades, síntomas y medicamentos. En Rejtman, los cuerpos se nombran, se hablan, se narran, se describen, apelando a la dimensión performativa del lenguaje que construye lo que enuncia. Se trata de identidades entramadas en los cuerpos y en los discursos sociales que los han constituido, los discursos científicos, médicos, jurídicos, filosóficos, pero también los discursos de los medios de comunicación, los discursos de la literatura y del cine. 
Sin embargo, en ocasiones estos cuerpos también logran revelarse tratando de deshacerse de ellos. Si el cuerpo-objeto en las películas de Rejtman denuncia el carácter de bien de mercado en que se han convertido las personas, también es cierto que muchos de sus personajes logran deshacerse del imperativo económico y generan un valor-otro, un valor propio, no económico, a partir del capricho, del sinsentido, que revierte la racionalidad moderna. Por lo general, se trata de un volver a empezar, como de un volver al grado cero de la significación de los cuerpos para desligarlos de las tradiciones discursivas que los han constituido. 


\section{Bibliografía}

\section{Bibliografía primaria}

Rejtman, M. (2007) [1992]. Rapado. Buenos Aires: Interzona.

Rejtman, M. (2011) [1996]. Velcro y yo. Buenos Aires: Mondadori.

\section{Filmografía citada}

Los Guantes Mágicos (2003). Dir. Martín Rejtman. Guión: Martín Rejtman. Con: Valeria Bertucelli, Susana Pampin, Gabriel Fernández Capello, Fabián Arenillas, Diego Olivera, Leonardo Azamor y Cecilia Biagini. Argentina: Pandora Film. 90 min.

Rapado (1992). Dir. Martín Rejtman. Guión: Martín Rejtman. Con: Mirta Busnelli, Ezequiel Cavia, Horacio Peña y Damián Dreizik. Argentina. 75 min.

Silvia Prieto (1999). Dir. Martín Rejtman. Guión: Martín Rejtman. Con: Rosario Bléfari, Valeria Bertucelli, Mirta Busnelli, Luis Mancini, Susana Pampin, Marcelo Zanelli y Gabriel Fernández Capello. Argentina. 90 min.

\section{Bibliografía secundaria}

Agamben, G. (1998). Homo Sacer I. Valencia: Pretextos.

Aguilar, G. (2010). Otros mundos. Un ensayo sobre el nuevo cine argentino. Buenos Aires: Santiago Arcos.

Bernini, E. (2008). Estudio Crítico sobre Silvia Prieto. Entrevista a Martín Rejtman. Buenos Aires: Picnic.

Butler, J. (1990). Gender trouble: feminism and the subversion of identity. New York: Routledge. 
Butler, J. (1993). Bodies that matter: on the discursive limits of "sex". New York: Routledge.

De Lauretis, T. (1989). Technologies of Gender. Essays on Theory, Film and Fiction. London: Macmillan Press.

Deleuze, G. (1991). "Posdata sobre las sociedades de control". C. Ferrer (Comp.). El lenguaje libertario. Tomo 2. Montevideo: Nordan.

Drucaroff, E. (2011). Los prisioneros de la torre: política, relatos y jóvenes en la postdictadura. Buenos Aires: Emecé.

Foucault, M. (1976). Histoire de la sexualité. 1. La volonté de savoir. París: Gallimard.

Foucault, M. (1992). La verdad y las formas jurídicas. Barcelona: Gedisa.

Gordon, R. (2011). "Cine y literatura en Martín Rejtman: estética de la inercia y contemporaneidad". Revista de Crítica Literaria Latinoamericana. Año XXXVII, $\mathrm{N}^{\circ}$ 73: LimaBoston. 1er semestre de 2011, pp. 289-305.

Haraway, D. (1995). Ciencia, Cyborgs y mujeres. La reinvención de la naturaleza, Madrid: Cátedra.

Le Breton, D. (2002). Antropología del cuerpo y modernidad. Buenos Aires: Nueva Visión.

Preciado, B. (2002). Manifiesto contra-sexual. Madrid: Opera Prima.

Preciado, B. (2014). Testo yonqui: sexo, drogas y biopolítica. Buenos Aires: Paidós.

Sanjurjo, M. (2007). "Derivas de la identidad en la filmografía de Martín Rejtman”. Cines al margen. Nuevos modos de representación en el cine argentino contemporáneo. M. J. Moore y P. Wolkowicz (Eds). Buenos Aires: Libraria, pp. 137150. 
Sarlo, B. (2003). "Plano, repetición: Sobreviviendo en la ciudad nueva”. A. Birgin y J. Trímboli (Comps). Imágenes de los noventa. Buenos Aires: Libros del Zorzal, pp. 125-149.

Sibilia, P. (2005). El hombre postorgánico. Cuerpo, subjetividad y tecnologías digitales. Buenos Aires: Fondo de Cultura Económica.

Sloterdijk, P. (2003). "El hombre operable. Notas sobre el estado ético de la tecnología". Revista Laguna. $\mathrm{N}^{0}$ 14, marzo, pp. 9-22.

Fecha de recepción: 7/6/2014

Fecha de aprobación: 2/5/2015 